\title{
Study of Using Weighting Property Index for Selecting the Best Maintenance Management System (MMS) at Power Plants
}

\author{
Lamyaa M. Dawood, May G. Kassir, Fadhil N. Mahan \\ Production Engineering and Metallurgy Department, Industrial Engineering Division, University of \\ Technology \\ lamya_alkazaai@yahoo.com,may_kassir@yahoo.com, fadhilnassrallah@yahoo.com
}

\begin{abstract}
To make Power Plants (PPs) economical, the maintenance functions should be optimized by carefully selecting and planning the Maintenance Management System (MMS) that will address the maintenance needs of the plant at the least cost. This research was carried out to obtain a clear understanding of the Traditional method and to assess their suitability to selection the management system of maintenance in power plants in Iraq. The objective of the study was to select the most suitable MMS for Maintenance of Electric Power Plants (MEPP) to make the plants operate economically. The traditional method called Weighting Property Index (WPI) used for selecting MMS for MEPP. This method, which is based on weighting property method (WPM) uses a digital logic (DL) due to, makes the result more accurate because it eliminates the problem of the criteria have least important. The research showed, when applied the method (WPI), the results was indicate that the preventive maintenance, is one of the types of planned maintenance, and is the best strategy for MMS in implementation the works (MEPP) in Iraq, where was arranging the alternatives generally according to results which was obtained from the method (WPI) as follows; preventive maintenance is (6.67), predictive maintenance is (6.07), proactive maintenance is (5.89), run to failure is (5.5), and unplanned failure is (5.33). For further research can be used operational KPIs with maintenance KPIs and use of another alternative is design out maintenance with other alternatives.
\end{abstract}

Keywords: Maintenance, KPI, WPI, Preventive maintenance, planned maintenance, digital logic, Maintenance Management System (MMS).

Paper History: (Received: 13/4/2017; Accepted: 1/6/2017)

\section{1- Introduction}

In today's environment, Maintenance Management System (MMS) is wide expands for process plants to increase profitability by improving reliability and achieving maintenance excellence. Maintenance is accepted as a means of gaining additional control of operational budgets and significantly increasing in productivity.

When consider that maintenance costs can make up 40 to $50 \%$ of operational budgets in capitalintensive industries, the effect of a reduction in maintenance costs is both obvious and impressive. In addition, maintenance is generally the largest controllable operating cost of a capital investment industry [1].

According to Jureen Thor et al., maintenance has emerged since the construction of physical structures such as power plants and machines. In general, maintenance is defined as the combination of all technical and administrative actions, including supervision and action indented to retain the machine or restore it to a state in which it can perform a required function [2].

Effective MMS ultimately aims to determine suitable action's that can keep power plants performance at acceptable level and extend the life cycle of the machine. Different types of MMS alternatives have been proposed to achieve the ultimate goal.

The selection of an optimum MMS is critical. The aim of the best MMS is to reduce the downtime of equipment and increase the availability of equipment. Every machine or equipment in an industry has its own reliability and phases of life cycle. So it is mandatory to adopt MMS in maintenance of industrial plants [2].

(Mohammed J. et. al., 2011)) Presented Weighting Property Method (WPM) to combine selection of materials (SM) processes during the early stages of design has previously been realized. In this work, an attempt is made to ensure that there is no gap between function oriented design and the material. A methodology is being developed, for a concurrent qualitative selection of materials method (CQSM) that takes into consideration the importance of materials properties in the early design stages. In the present investigation, a new numerical method has been build by using visual basic developed 
select materials for mechanical design in conceptual stage. This method, which is based on weighting property method (WPM) uses a new digital logic (DL) comparison with the traditional (DL) makes the result more accurate because it does not elimination problem of the least important criterion [3].

(Suresh Talur et. al., (2015)) applied Weighted Property Method (WPM) to selected suitable material for blades, for manufacturing of small scale Savonius Vertical Axis Wind Turbine (SVAWT), material considered for manufacturing of SVAWT are Aluminium (7020 Alloy), Mild Steel (grade 55), Stainless Steel (A580) and Polycarbonate sheet, among these optimized material should be selected to increase performance of wind turbine, the selected materials for SVAWT must shows low density, corrosion resistant, economic, good machinability and good mechanical properties [4].

\section{Maintenance Strategies}

Maintenance strategies used in this paper are given below;

\subsection{Predictive Maintenance}

The PM is used to represent the maintenance strategy that is able to forecast the temporary trend of performance degradation and predict faults of machines by analyzing the monitored parameters of data. Fault prognostic is a growing technology used in maintenance management system. It offers the possibility of planning the maintenance operation based on the time of future failure and coincidence with maintenance activities, production plans, customers' orders and personnel availability. PM can guide the maintenance personnel to plan the availability of right spares and tools in right time and hence the maintenance cost is greatly reduced [5].

\subsection{Preventive Maintenance}

All actions carried out on a planned, periodic and specific schedule to keep an item/equipment in stated working condition through the process of checking and reconditioning [6].

\subsection{Design Out Maintenance (DOM)}

Another prevalent maintenance policy is basically used to facilitate maintenance or reduce the need for maintenance by modifying machine components. DOM is usually implemented when problems continue to occur despite the application of other maintenance policies. Imperative factors to consider in DOM include reliability, modularity, standardization, and ergonomics of the components and the machine. The adoption of maintenance alternative can vary from one machine to another or within the industry. Therefore, an optimal decision can only be reached in the presence of a systematic and visibly distinct decision-making approach. The adopted approach can verify and assess the respective characteristics and criteria of maintenance alternatives weighed against industry requirements and limitations [7].

\subsection{Corrective Maintenance}

The main feature of corrective maintenance is that actions are only performed when a machine breaks down. There are no interventions until a failure has occurred and also called run to failure [8].

\section{Proposed Methodology 3.1. Weighted Property Index}

Weighted property method is very useful when there are a lot of important requirements or alternatives to compare and evaluate as shown in Figure 1 [9]. A WPI is obtained by multiplying the property value by the weighting factor $\left(w_{i}\right)$. Since different properties have widely different numerical values, each property must be scaled that the largest value does not exceed 100 according to Equation 1 [10].

$\breve{\mathrm{S}}=$ scaled property $=$ (numerical value under
consideration /
consideration) 100

For properties such that it is more desirable to have low values, e.g., density, corrosion loss, cost, environmental effects and electrical consumption, the scale factor is formulated as shown in 2.

$$
\begin{gathered}
\breve{\mathrm{S}}=\text { scaled property }=\text { (lowest value under } \\
\text { consideration / numerical value of property) }
\end{gathered}
$$

$$
100
$$

There are two general schemes for working with the weighting factors. The most common one is to set $W i<1$, such that $\sum W i=1$. The other is to let $w$ take on a range of values, with the largest value denoting the property of greatest importance [11].

When many maintenance strategies are used to specify performance, it may be difficult to establish the weighting factors. One way to do so is to use a digital logic (DL) approach. Each property is listed and is compared in every combination, taken two at a time. To make the comparison that is considered to be more important of the two is given a (1) and the less important property is given a zero.

This method, which is based on weighting property method (WPM) uses a digital logic (DL) due to, makes the result more accurate because it eliminates the problem of the criteria have least important. Using the digital logic (DL) approach, evaluations are arranged in such way that only two criteria are considered at a time. Every possible combination of criteria or performance goals is compared and no shades of choice are required; only a yes or no decisions 
for each valuation $[10,11 \& 12]$. In most application, the selected MMS should satisfy more than one maintenance requirements. This method was adopted because there are a number of criteria for the selection of an alternative from set of alternatives, therefore applied WPI according to the following below.

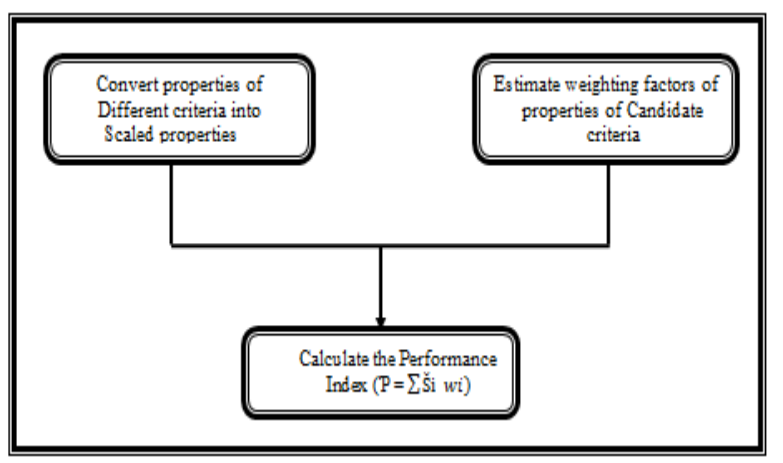

Figure 1: Weighted property Index

\begin{abstract}
3.1.1. Ranking and Weighting for Attributes
In comparing two properties or goals, the more important goal is given numerical one (1) and the less important is given zero (0). To determine the relative importance of each criteria or goal a table is constructed by using Excel Program. The criteria or goals are listed in the left hand column, and comparisons are made in the columns to the right, as shown in Table 1.
\end{abstract}

(1): means that there is a relationship between the two properties.

(0): there is no other relationship, and the cell matrix ${ }^{*}$ is left without No.

Where, the given weights estimated according to personal interviews with engineers experts, specialists in this field and questionnaire results.

Where Digital Logic Method (DLM) is a method defines the relationship between the criteria by using a matrix, the matrix cells fills as follows: (1) means that there is a relationship between the two standards, (0) there are no other relationship and leave the cell matrix without No.

By using the Equations $3 \& 4$ at Appendix B will be calculate the total number of possible conditions. Weight factor are made in the last columns to the right in Table 2.

$$
\begin{aligned}
& N=\mathrm{n}(\mathrm{n}-1) / 2 \\
& \mathrm{~W}_{\mathrm{i}}=\mathrm{mi} / \mathrm{N}
\end{aligned}
$$

Where:

$\mathrm{N}$ : Total number of possible conditions

$\mathrm{n}$ : Number of criteria

$\mathrm{m}$ : Total number of positive conditions for each criterion

i: Summed over all the criteria

Table 2 lists the weights of eight criteria by positive decision, for example (3) for (staff training) when the application required eight criteria. The relative importance is divided into 8 points scale. From Table 2, the value of (1) is to the less important criterion etc., (personal safety) (5) to the more important criterion one etc., (maintenance cost, fuel type and crew size) and (7) (environment effect) to the more important than (3) (maintenance performance). With this method approach the lesser important criterion still remains in the selection list. The Relative emphasis coefficient or weighting factor (Wi) for each property is obtained by dividing the number of positive decision for each criterion into the total number of possible decisions.

\subsubsection{Calculate Key Performance Indicators}

The purpose of this study to selection suitable of MMS according to some criteria such as reliability, availability, and efficiency of scheduled maintenance for electric power plants. Ultimately is to selection the best maintenance management system.

According to type of failure and maintenance strategy used to calculated (MTTR, MTBF), to calculated $R(t), A(t)$, Maintainability (MAI)), then found the Maintenance Performance (MP), according to Equations 5, 6, 7, 8, 9, 10, $11 \& 12$. In Matlab program (Version R2012a) it was integrated with directly to Excel program for calculate (MTTR, MTBF, $R(t), A(t), M A I, M P)$. $M T T R=\frac{\tau}{N}$

$$
\begin{aligned}
& \lambda=\frac{\text { numbers of failures }}{\text { unit operating time }} \\
& \mu=\frac{1}{M D T} \\
& A=\frac{\mu}{\mu+\lambda}=\frac{M T B F}{M T B F+M T T R}=\frac{\text { Uptime }}{\text { Uptime }+ \text { Downtime }} \\
& R(t)=\exp (-t / M T B F)=\exp ^{-\lambda t} \\
& \text { Maintainability }=\exp (-t / M T T R)=\exp (-\mu t \text {. } \\
& \text { (10) } \\
& \mathrm{MP}=\text { Reliability } \times \text { Availability } \\
& \operatorname{MTTR}(\text { Mean time to repair })= \\
& \text { total repair time } \\
& \overline{\text { Number of breakdowns }}
\end{aligned}
$$

Where:

MTBF: Mean Time Between Failures, MTTR: Mean Time To Repair,

$A$ : Availability, $\lambda$ : Failures rate, $\mu$ : Repairs rate, $\quad R(t)$ : Reliability, $N$ :Number of failures, $\tau$ : Total outage time

\section{Case Study \\ Power Plant South of Baghdad / Gas- 2}

In this research is study power plant South of Baghdad / Gas- 2 as a case study to examine the use of method (WPI) to choose the suitable of (MMS) used in the maintenance of power plants. Using equations in paragraph (3.1.2), the values were generated. The following Tables are 
summary of generated after being processed in the code program using Matlab Program Version Ra 2014.

Notes of these data, convergence in the results, so for several reasons, are:

- The four units are from one type (Frame 5)

- The four units are from the same company (General Electric).

- The same operational life.

- The same staff is assigned for operation and maintenance.

- The same fuel is used in the four units.

Table 4 shows the results account of the MP, for four gaseous units from power plant south of Baghdad/ Gas- 2. Details calculations of MP by using the Equation 11 and these results are summarized using Code Program in Matlab software. These results shows, that the MP was the highest when using preventive maintenance at all units. In addition to a large convergence between the results for (MPI) for the four units of the power station south of Baghdad/ Gas 2, for the following reasons:

1. The units of the same model and operational lifetime.

2. The same fuel used (HFO).

3. Maintenance team is the same for the four units.

4. The Number of stops for the four units convergent among them.

5. The maintenance type used is the same for the four units.

Table 3 summarize result of code program in Matlab for Power Plant South of Baghdad/ Gas-2

Table 4 summarize result of code program in Matlab for Power Station South of Baghdad/Gas-2.

\section{Results and Dicusion}

Through the results shown in the Tables 5, for four gaseous units of the South of Baghdad Power Plant /Gas-2, the performance index values are higher by using preventive maintenance in implementation of maintenance work at all units, where the imposition of importance scale for sub criteria, starting from (1) means less important and ending with (10) means higher importance. The process to produce of performance index based on weighting method by using Excel program 2010, for found performance index to selected best alternative. The results of each power plant are listed in Table 5 .

Summary of the results and the Figures to index performance shown in Figure 2 depict a simple difference between the types of planned maintenance, which are (preventive, proactive, predictive maintenance) for maintenance management system. This method also does not take completely the whole system, but parts of the system are taken separately, thus they do reflect a holistic view for the system. Results showed that the planned maintenance is the better than unplanned maintenance for electric power plants. Through results of WPI, it is shown that the preventive maintenance used in the maintenance of electric power plants is better than other types of maintenance, although it could not be used alone, conjugated with other maintenance strategies for implementation of maintenance activities.

\section{Conclusion}

1. Selection of proper MMS can highly affect in reducing cost, improving quality and power plants reliability, increasing productivity and as a result achieving organizational goals and objectives.

2. In this research for selecting best MMS, using WPI methodis proposed, by using a set of alternatives for maintenance strategies are (Unplanned failure, Run-tofailure, Proactive, Preventive, and Predictive maintenance) and set of KPIs like: four main Criteria (Environment, Safety, Maintenance, Operation) and 8 subcriteria (Maintenance performance, Personal safety, Maintenance cost, Environment effect, Fuel type, Staff training, Quality rate, and Crew size).

3. Applying (WPI) methods, shown the results that through score values and performance index values respectively that the best option is using preventive maintenance for MMS in the implementation of maintenance activities for all gaseous plants.

4. The highest value of the alternative according to the results which was obtained from the method WPI, where was indicate to the preventive maintenance, which is one of the types of planned maintenance, is the best for MMS in implementation the activities (MEPPs) in Iraq. South Baghdad Power Plant/Gas -2 was (Unplanned failure (5.32), Run-to-failure (5.5), Proactive (5.89), Preventive (6.67), and Predictive maintenance (6.07)). For further research can be used predictive/monitoring KPIs with maintenance KPIs and use of another alternative is design improvement maintenance with other alternatives.

\section{References}

[1]. Azhar N. A. Che, and Mansor M. A. , Development of Plant Maintenance Management System (PMMS): A Case Study, Materials Science and 
Engineering, University Malaysia Pahang, Pahang, Malaysia, 50, (2013).

[2].Jurrenthor, Siewhong Ding, and Shahrulkamarddin, Comparison of MultiCriteria Decision Making Methods from the Maintenance Alternative Selection Perspective, International Journal of Engineering and Science, 65, (2013), 2319- 1805.

[3].Mohammed J., Mithal A. and Suad H., Materials Selection in Conceptual Design using Weighting Property Method, Journal Engineering and Technology, 29, ( 1), (2011).

[4].Suresh T., Kiran K.. P., and Madhusudhan T., Selection of Material by Weighted Property Method for Savonius Vertical Axis Wind Turbine Rotor Blade, International Research Journal of Engineering and Technology (IRJET), 02, (1), (2015), 66-72.

[5].Al-Najjar, B. and Alsyouf I., Selecting the most Efficient Maintenance Approach Using Fuzzy Multiple Criteria Decision Making, International J. Production Economics, (2003), 84.

[6].Esmaeili M., Seyedi S. M., Iranban S. J., Determining Maintenance Strategy by Using Fuzzy Group MADM Approach, European Online Journal of Natural and Social Sciences, 2(3), (2013).

[7].Jureen T., Siew-Hong D. , Shahrul K., Comparison of Multi Criteria Decision Making Methods From The Maintenance Alternative Selection Perspective, The International Journal Of Engineering And Science, Vol. 2, (2013), 27-34, Issue 6,
[8].Odeyale S.O., Alamu O.J. , and Odeyale E.O., The Analytical Hierarchy Process Concept for Maintenance Strategy Selection in Manufacturing Industries, The Pacific Journal of Science and Technology, 14, (1), (2013).

[9].Shankar C. and Prasenjit C., Selection of Materials Using Multi-Criteria Decision-Making Methods with Minimum Data, Decision Science Letters, 2, (2013), 135-148, www.GrowingScience.com/dsl.

[10].Katica S., Mario G., Goran S., and Ilija S., Applying of AHP Methodology and Weighted Properties Method to the Selection of Optimum Alternative of Stock Material, ACTA Technica Corvininsis-Bulletin of Engineering, Faculty of Engineering- Hunedoara, Romania, 2009.

[11].Chen F. L. and Chen Y. C., Evaluating the Maintenance Performance of the Semiconductor Factories Based on the Analytical Hierarchy Process and Grey Relational Analysis, American Journal of Applied Sciences, 7, (4), (2010), 568-574.

[12].Suresh T., Kiran K.. P., and Madhusudhan T., Selection of Material by Weighted Property Method for Savonius Vertical Axis Wind Turbine Rotor Blade, International Research Journal of Engineering and Technology (IRJET), 02, (1), (2015).

Table (1): Relative Importance of Weighting Factors Using (DL)

\begin{tabular}{|c|c|c|c|c|c|c|c|c|c|c|c|c|c|c|c|c|c|c|c|c|c|c|c|c|c|c|c|c|c|}
\hline & Criteria & $1-2$ & $1-3$ & $1-4$ & $1-5$ & $1-6$ & $1-7$ & $1-8$ & $2-3$ & $2-4$ & $2-5$ & $2-6$ & $2-7$ & $2-8$ & $3-4$ & 3-5 & $3-6$ & $3-7$ & $3-8$ & $4-5$ & $4-6$ & $4-7$ & $4-8$ & $5-6$ & $5-7$ & $5-8$ & $6-7$ & $6-8$ & 7-8 \\
\hline 1 & $\begin{array}{c}\text { Environment } \\
\text { effect }\end{array}$ & 1 & 1 & 1 & 1 & 1 & 1 & 1 & & & & & & & & & & & & & & & & & & & & & \\
\hline 2 & $\begin{array}{c}\text { Maintenance } \\
\text { cost }\end{array}$ & 0 & & & & & & & 0 & 1 & 0 & 1 & 0 & 1 & & & & & & & & & & & & & & & \\
\hline 3 & crew size & & 0 & & & & & & 1 & & & & & & 0 & 0 & 0 & 0 & 0 & & & & & & & & & & \\
\hline 4 & $\begin{array}{l}\text { Maintenance } \\
\text { performance }\end{array}$ & & & 0 & & & & & & 0 & & & & & 1 & & & & & 0 & 0 & 1 & 1 & & & & & & \\
\hline 5 & $\begin{array}{l}\text { Personal } \\
\text { Safety }\end{array}$ & & & & 0 & & & & & & 1 & & & & & 1 & & & & 1 & & & & 1 & 0 & 1 & & & \\
\hline 6 & fuel type & & & & & 0 & & & & & & 0 & & & & & 1 & & & & 1 & & & 0 & & & 1 & 1 & \\
\hline 7 & staff Training & & & & & & 0 & & & & & & 1 & & & & & 1 & & & & 0 & & & 1 & & 0 & & 0 \\
\hline 8 & qulity rate & & & & & & & 0 & & & & & & 0 & & & & & 1 & & & & 0 & & & 0 & & 0 & 1 \\
\hline & & & & & & & & & & & & & & & & & & & & & & & & & & & & & \\
\hline
\end{tabular}


Table (2) results of relative importance of weighting factors using the DL method

\begin{tabular}{|c||c||c|c|}
\hline No. & Sub-criteria & $\begin{array}{c}\text { Positive } \\
\text { decisions }\end{array}$ & $\begin{array}{c}\text { Weighting } \\
\text { factor } w_{i}\end{array}$ \\
\hline \hline 1 & Environment effect & 7 & 0.25 \\
\hline 2 & Maintenance cost & 3 & 0.11 \\
\hline 3 & Crew size & 1 & 0.04 \\
\hline 4 & Maintenance performance & 3 & 0.11 \\
\hline 5 & Personal Safety & 5 & 0.18 \\
\hline 6 & Fuel Type & 4 & 0.14 \\
\hline 7 & Staff Training & 3 & 0.11 \\
\hline 8 & Quality Rate & 2 & 0.07 \\
\hline
\end{tabular}

Table (3) summarize result of code program in Matlab for Power Plant South of Baghdad/ Gas-2

\begin{tabular}{|c||c|c|c|c|}
\hline & $\mathrm{U}_{1}$ & $\mathrm{U}_{2}$ & $\mathrm{U}_{3}$ & $\mathrm{U}_{4}$ \\
\hline \hline$M T T R$ & 0.6980 & 1.0706 & 0.7496 & 0.8128 \\
\hline$M T B F$ & 9.4284 & 11.6715 & 11.3275 & 10.4073 \\
\hline$R(t)$ & 0.2037 & 0.2766 & 0.2660 & 0.2366 \\
\hline$A(t)$ & 0.9311 & 0.9160 & 0.9397 & 0.9276 \\
\hline$M A I$ & 0.9770 & 0.9649 & 0.9753 & 0.9733 \\
\hline
\end{tabular}

Where: (U) is generating unit.

Table (4) summarize result of code program in Matlab for Power Station South of Baghdad/Gas-2

\begin{tabular}{|c|c|c|c|c|c|c|c|c|c|}
\hline \multicolumn{5}{|c|}{ South of Baghdad Power Plant/Gas 2 Unit 1} & \multicolumn{5}{|c|}{ South of Baghdad Power Plant/Gas 2 Unit 2} \\
\hline \multicolumn{2}{|c|}{ Alternatives } & 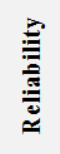 & 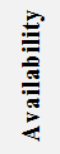 & 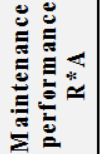 & \multirow{2}{*}{\multicolumn{2}{|c|}{ Alternatives }} & \multirow{2}{*}{ 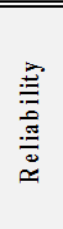 } & \multirow{2}{*}{ 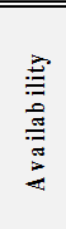 } & \multirow{2}{*}{ 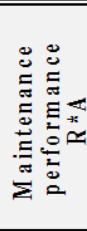 } \\
\hline \multirow{2}{*}{$\begin{array}{l}\text { Unplanned } \\
\text { Maint. }\end{array}$} & Unplanned failure & 0.39 & 0.93 & 0.36 & & & & & \\
\hline & Run to failure & 0.39 & 0.93 & 0.36 & \multirow{2}{*}{\begin{tabular}{|c|}
$\begin{array}{c}\text { Unplanned } \\
\text { Maint. }\end{array}$ \\
\end{tabular}} & Unplanned failure & 0.42 & 0.92 & 0.39 \\
\hline \multirow{3}{*}{$\begin{array}{l}\text { Planned } \\
\text { Maint. }\end{array}$} & Preventive & 0.53 & 0.93 & 0.49 & & Run to failure & 0.42 & 0.92 & 0.39 \\
\hline & Proactive & 0.53 & 0.93 & 0.49 & \multirow{3}{*}{$\begin{array}{l}\text { Planned } \\
\text { Maint. }\end{array}$} & Preventive & 0.65 & 0.92 & 0.60 \\
\hline & Predictive & 0.53 & 0.93 & 0.49 & & Proactive & 0.65 & 0.92 & 0.60 \\
\hline & & & & & & Predictive & 0.65 & 0.92 & 0.60 \\
\hline \multicolumn{5}{|c|}{ South of Baghdad Power Plant/Gas 2 Unit 3} & \multicolumn{5}{|c|}{ South of Baghdad Power Plant /Gas 2 Unit 4} \\
\hline \multicolumn{2}{|c|}{ Alternatives } & 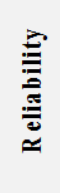 & 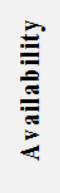 & 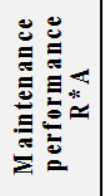 & \multirow{2}{*}{\multicolumn{2}{|c|}{ Alternatives }} & 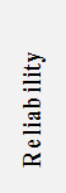 & 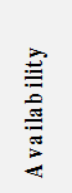 & 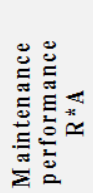 \\
\hline \multirow{2}{*}{$\begin{array}{l}\text { Unplanned } \\
\text { Maint. }\end{array}$} & Unplanned failure & 0.41 & 0.94 & 0.39 & & & & & \\
\hline & Run to failure & 0.41 & 0.94 & 0.39 & \multirow{2}{*}{\begin{tabular}{|c|}
$\begin{array}{c}\text { Unplanned } \\
\text { Maint. }\end{array}$ \\
\end{tabular}} & Unplanned failure & 0.38 & 0.93 & 0.35 \\
\hline \multirow{3}{*}{$\begin{array}{l}\text { Planned } \\
\text { Maint. }\end{array}$} & Preventive & 0.64 & 0.94 & 0.60 & & Run to failure & 0.38 & 0.93 & 0.35 \\
\hline & Proactive & 0.64 & 0.94 & 0.60 & \multirow{3}{*}{$\begin{array}{c}\text { Planned } \\
\text { Maint. }\end{array}$} & Preventive & 0.62 & 0.93 & 0.58 \\
\hline & Predictive & 0.64 & 0.94 & 0.60 & & Proactive & 0.62 & 0.93 & 0.58 \\
\hline & & & & & & Predictive & 0.62 & 0.93 & 0.58 \\
\hline
\end{tabular}


Table (5) results of Performance index for South of Baghdad/Gas-2

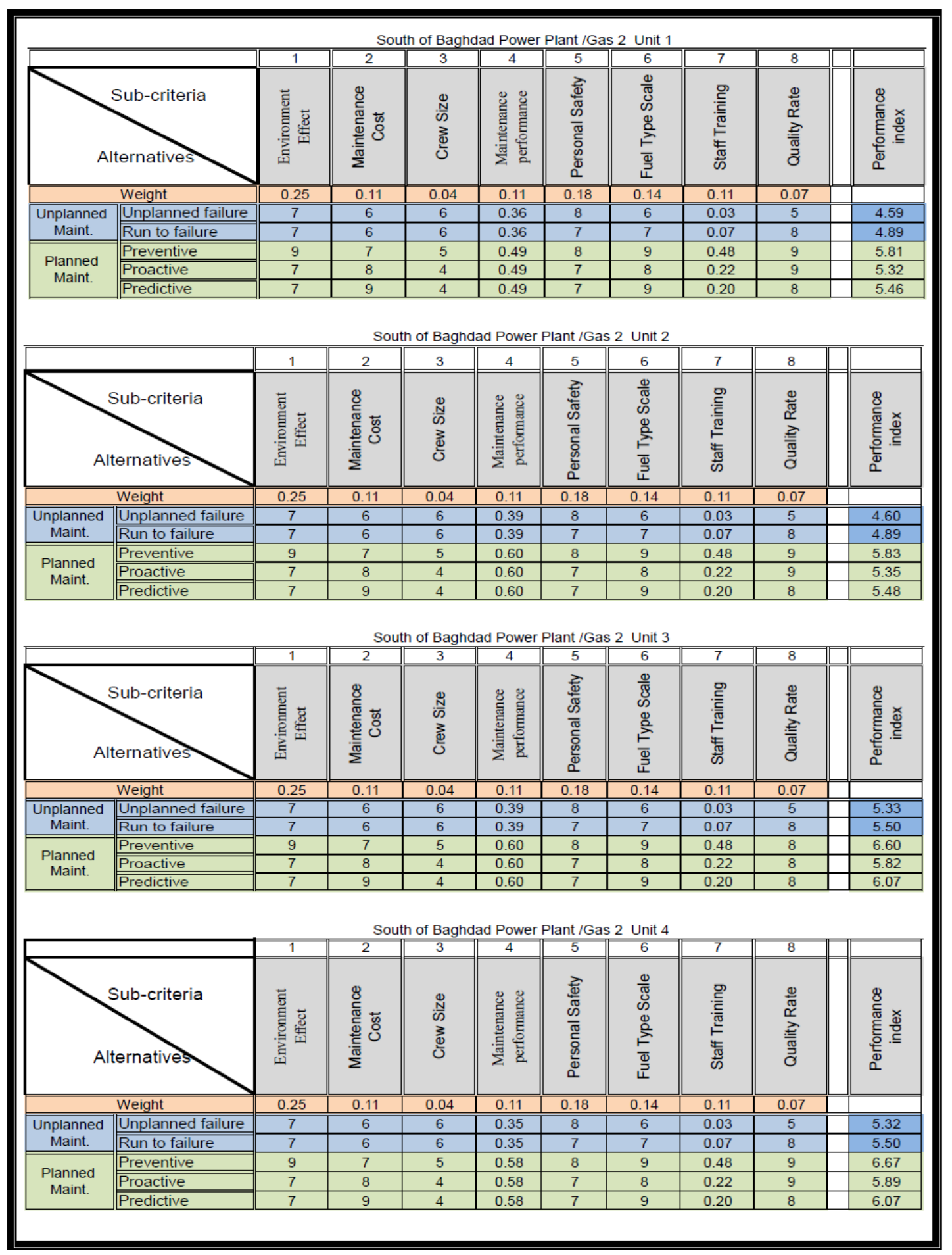

Table (6) Summary results of performance index

\begin{tabular}{|l|c|c|c|c|}
\hline \multicolumn{1}{|c|}{ Units } & U1 & U2 & U3 & U4 \\
\hline Unnlannedives failuer & 4.059 & 4.6 & 5.33 & 5.32 \\
\hline Run to failer & 4.089 & 4.89 & 5.5 & 5.5 \\
\hline Preventive & 5.81 & 5.83 & 5.6 & 6.67 \\
\hline Proactive & 5.32 & 5.35 & 5.82 & 5.89 \\
\hline Predictive & 5.46 & 5.48 & 6.07 & 6.07 \\
\hline
\end{tabular}




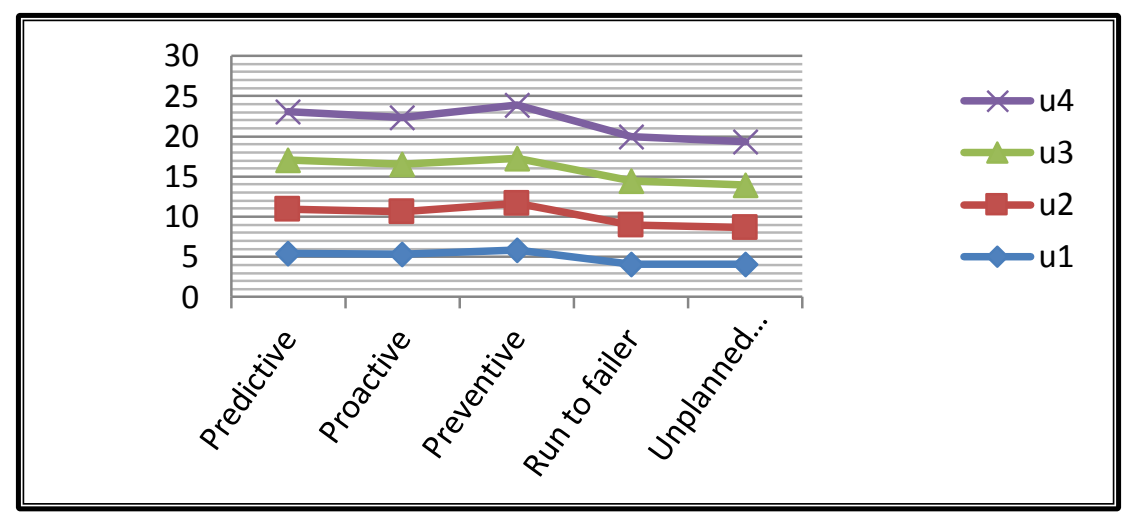

Figure (2) Summary results of performance index 